\title{
IMPORTÂNCIA DOS INSTINTOS SEXUAIS EM PSICOPATOLOGIA
}

\author{
DARCY M. UCHôA *
}

O progresso da Psicopatologia vem se caracterizando pelo esfôrço no sentido de serem apreendidos os fatôres básicos da personalidade humana que a predispõem a claudicar sob o impacto dos mais variados agentes agressivos. A consideração analítico-descritiva foi superada, representando mero conteúdo manifesto de tôda uma rica latência que palpita por trás da fachada sintomatológica. A busca de causas completa-se pela inquirição sôbre o sentido dos sintomas, esforçando-se o psicopatologista para estudar a personalidade como um todo único, não suscetível de interpretação quando dissociado em fragmentos, partes ou categorias. Investiga-se em cada personalidade que sofre o sentido vital do sofrimento, as falhas das técnicas defensivas que em todos os niveis visam a proteção do organismo contra as agressões que sofre em seu desenvolvimento e em sua manutenção. A Psicologia Normal, a Psicopatologia e a Medicina Psicossomática estão impregnadas de concepções psicodinâmicas que, sem dúvida, explicam seus notáveis progressos.

Kraepelin é considerado como o grande sistematizador da moderna Psiquiatria, tendo sua obra sêlo de genialidade porque sistematizadora e criadora. Todavia, em sua grande preocupação de colocar a Psiquiatria dentro do critério científico válido para as ciências físico-naturais, criou sistemas nosográficos com grandes entidades nosológicas, para elas postulando e buscando, algo artificialmente, precisas etiologias, decursos e estados terminais, não raro o prognóstico decidindo a rotulação diagnóstica.

A crítica ao edifício construido pelo mestre de Munich não tardou, cumprindo registrar que o progresso foi realizado em ordem e sistematização, mas não no sentido da penetração dos problemas e conflitos básicos do doente mental. O marco inicial dessa revolução psiquiátrica consistiu na descoberta de Breuer e Freud exposta no ensaio de 1893: "Sôbre o mecanismo psíquico dos fenômenos histéricos" ${ }^{4}$. A técnica inicial psicocatártica, com a análise em hipnose, foi superada e substituída pela associação livre de idéias e a interpretação, mas o marco fundamental foi lançado quando Brєuer descobriu a extraordinária importância de traumas emocionais do passado, de constalaçōes ideoafetivas retidas no interior da personalidade. Estava demonstrada a necessidade, fundamental para o psiquiatra e para o

* Livre Docente de Psiquiatria na Faculdade de Medicina da Universidade de São Paulo e na Faculdade Nacional de Medicina da Universidade do Brasil. 
psicoterapeuta, de penetrar no mais profundo da personalidade enfêrma para apreender os fatôres essenciais da causalidade mórbida.

Freud não se contentou com a teoria dos estados hipnóides postulada por Breuer e logo descobriu a importância da vida sexual na etiologia das neuroses. Se queremos estudar ou reavaliar o problema dos instintos sexuais em psicopatologia, temos de iniciar com Freud e suas originais descobertas da sexualidade infantil, já entrevista, aliás, pelo pediatra Lindner. Não subestimamos a obra de um Havelock Ellis, grande sexologista, de um Forel e, muito menos, a "Psicopatologia sexual" de um Kraft-Ebing; mas, se refletirmos sôbre o material apresentado em forma descritiva, não retiramos dêle grandes dados e ensinamentos, pois são estudos descritivos, importantes sem dúvida pelo escopo educativo, mas sem profundidade para os esclarecimentos dos problemas etiopatogênicos, quase todos girando em tôrno do então famoso problema das degenerações mentais. Com Freud, o problema sexual encaminhou-se para algo mais preciso e específico. Com constância, nas associações e recordações dos pacientes surgiam fatos de sedução sexual, traumas, conflitos em tôrno do problema da masturbação e outros de natureza erótica, mêdo e culpa em face dos genitores, logo interiorizados naquilo que ulteriormente a terminologia psicanalítica denominou "consciência moral" e, depois, "superego". O material que Freud acumulou até publicar seu clássico ensaio de $1905^{\text {ja }}$ foi obtido pelas associações e recordações dos pacientes; todo êle seria corroborado pelos estudos ulteriores de psicanálise infantil (Ana Freud, Sophie Morgenstern, M. Klein e sua escola, e outros pedanalistas).

Na moderna psicopatologia, reavaliar o papel dos instintos sexuais significa estudar a importância, possivel incorreção ou insuficiência da teoria da libido postulada por Freud. Concebeu êle a sexualidade como algo bem mais amplo do que a genitalidade. Em essēncia, segundo Freud, os instintos sexuais visam, quando satisfeitos, a consecução do prazer. A principio, apoiam-se nos instintos de nutrição - o prazer em nutrição - como, por exemplo, quando a criança se funde emocionalmente com a mãe no ato de amamentação; logo revelam-se algo independentes, como no uso da chupeta ou na sucção do polegar; quando o interêsse é deslocado para atividades digestivas intestinais, então, com o ato da evacuação, surge a componente prazerosa anal, para logo evolver no sentido do prazer fálico já localizado nos órgãos genitais. Assim, a libido, concebida como energia dos instintos sexuais, teria evolução tópica e dinâmica, com várias zonas erógenas prégenitais e componentes ou instintos parciais evolvendo para a unificação fálica, completando-se a sexualidade infantil aos 5-6 anos. Postula ainda Freud um periodo de latência logo a seguir, até às manifestações da pré-puberdade e puberdade prōprìamente ${ }^{5 u}$. Depoìs ocorrem fenômenos característicos endócrino-psicológicos que se sedimentam na sexualidade do adulto, para então surgir o declínio das atividades eróticas com a involução orgânica geral, da qual o climatério é mera fase crítica. A noção de instinto foi concebida como "um conceito limite entre o somático e o psíquico": tem êle uma fonte original no plano somático (zona erógena), um objeto e uma finalidade que é sua descarga, com a sensação prazerosa de algo que se satisfaz. Através dessas zonas erógenas, espécies de llhotas no erotismo geral do corpo humano, os instintos sexuais são concebidos como algo múltiplo, inștintos parciais evolvendo para a unificação da fase genital.

Abraham desdobrou cada uma dessas fases (oral, anal e fálica) em primária e secundária, e estudou suas relações com o problema da seleção de neuroses e psi- 
coses. Há "fixaçōes" e "regressōes" da libido ou do ego para tal ou qual zona sob o impacto das frustrações dos conflitos atuais, havendo irrupçăo de tal ou qual neurose de acôrdo com o ponto de fixação para o qual a libido regrediu. Freud, e com êle tôda uma plêiade de brilhantes discípulos na primeira fase do movimento psicanalitico, postulou, assim, a grande e decísiva importância da sexualidade no campo das neuroses, logo esforçando-se por aplicar a teoria da libido ao campo das psícoses com o clássico estudo do caso Schreber e com seu ensaio sôbre o nascisismo. Na evolução instintivo-afetiva, tornou-se importante o problema das relações com os objetivos primários, tendo sido estudado por Freud o clássico "complexo de Édipo" e o não menos importante "complexo de castraçāo", como pontos focais de extrema importância no curso do desenvolvimento pessoal.

Assim, a teoria dos instintos é de vital importância em psicanálise, os impulsos sexuais destacando-se pela sua extraordinária importância não só dentro da psicopatologia, mas também no plasmar a personalidade psiquicamente estável, sadia. Não existiu jamais o tão equivocadamente formulado pansexualismo, mas fôrça é reconhecer a grande predominância logo assumida, na teoria e técnica psicanaliticas, pelos instintos sexuais. Sua fôrça estêve sempre em sua base empirica, pois eram os fatos clínicos, o material vivo de recordações, fantasias, sonhos, atos falhos da vida cotidiana, tudo isso reunido por Freud, que sempre estava a justificar aquela predominância de Eros na vida normal como na psicopatológica. A observaçāo cuidadosa das crianças por māes, pediatras e educadores sempre tende a confirmar o material colhido pelo psicanalista, havendo, todavia, certos escotoInas, filhos de prejulgados filosófico-religiosos ou de resistências pessoais do observador, no sentido de registrar e compreender o material de atividades sexuais (reais ou fantasiadas) fornecido pela criança desde as primeiras fases do seu desenvolvimento. Freud jamais postulou o pansexualismo, percebendo, desde o inicio, a importância primacial da situação conflituosa. A importância da sexualidade advinha de ser ela parte constante de tal situação, sendo a outra o mêdo dos genitores, influxos educacionais e religiosos, ulteriormente introjetados sob forma de ego ideal, consciência moral, superego. A dualidade inicial (instintos sexuais e instintos de conservação do ego) não pôde se manter após a descoberta de que grande parte da sexualidade, sob forma de libido narcisica, também revestia o ego, protegendo-o, dando-lhe prazer, conservando-o portanto. $E$ no ensaio de 1922 , Freud lançou sua nova teoria: instintos sexuais ou de vida e instintos de morte, êstes, quando defletidos para o exterior, dando os fenômenos de agressão. Houve necessidade de ampliação do conceito do sexual para além do genital, para que pudessem ser melhor interpretadas as manifestạções da sexualidade infantil que visam não a reprodução, mas o prazer, como acontece também com os fenômenos das perversões sexuais. É conhecida a freqüência do onanismo infantil que se incrementa com as novas irrupcões libidinosas da puberdade, sempre proibido, por vêzes terrlficamente, mas sem que pais ou educadores assumam atitudes de compreensão para corrigí-lo. Os modernos trabalhos de pedanálise confirmam a importância da sexualidade infantil, que se origina com os próprios fenômenos orais da sucção ao seio, prolongando-se, através de atividades anais, até à fase fálica com atos e fantasias em estreita conexão com os objetos em que a libido é investida no curso de sua evoluçāo. Esta é conflituosa, e a importância e intensidade de tais conflitos dependem muito do tipo de educação que a criança vai recebendo, sendo vitais, portanto, a própria educação e formação dos pais, da mãe particularmente, nas primeiras fases. Através da familia, há o ponto de passagem da psicanálise, como psicologia individual, para o social, fazendo-se sentir as influências da tradição familiar e social na forma por que os pais se orientam na formação e educação dos filhos. Como resultado de tais situações conflituosas, que atingem o clímax aos 4-6 anos com o "complexo de Édipo", surgem, com regularidade, as neuroses infantis, consideradas como crise do desenvolvimento psicossexual.

Essa visāo interpretativo-compreensiva trazida pela psicologia dinâmica representou grande contribuição para os estudos da personalidade em geral, completando as demais técnicas de aproximação de tipo transversal, superficial, inclusive as pos- 
sibilitadas pelas orientações behaviorista, gestaltista e fenomenológica. Estas vão tomando em psicopatologia tôda sua importância pelos influxos e bafejos dessa visão em profundidade oferecida pelo gênio de Freud. Representou grande revolução na psicologia normal e na psicopatologia, impondo-se seus achados sôbre criticas o mais das vêzes dependentes de uma época de preconceitos contra as manifestacões biopsicológicas dos mais poderosos instintos que agitam a alma humana. Grande parte dêsses preconceitos já toi superada, o que possivelmente já está se refletindo sôbre a própria tipologia das neuroses, que vai variando em função de fatôres socioculturais a se refletirem na atitude de pais e educadores para com os impulsos básicos. A histeria de conversão do tempo de Charcot é raridade atualmente, as neuroses compulsivas vão se tornando menos frequientes também; são mais encontradiços os estados de impotência sexual masculina e de frigidez feminina, aumentando assustadcramente as neuroses de caráter e o comportamento psicopático nas novas gerações. Ésse é o grande ponto de convergência entre o biológico e o social que, de forma alguma, devem ser toncebidos como fôrças opostas, doutrinária ou conceptualmente, senão como causas conjugadas que se completam para a compreensão de fenômenos tão complexos. $\hat{E}$ todo o campo da moderna psicologia social e mesmo da antropologia cultural altamente impregnadas de conceitos psicodinâmicos.

Mesmo entre os mais fiéis e competentes colaboradores de Freud, houve alguns que não aceitaram suas idéias e descobertas referentes à importância etiológica da sexualidade nas neuroses. Adler considerou a sexualidade como um dos problemas vitais do homem, sendo os dois outros o profissional e o das relações sociais (sentimento de comunidade); procurou êle fundamentar sua psicologia individual sôbre a importância dos sentimentos de inferioridade, destacando o papel dos instintos de agressão e das técnicas usadas pela personalidade para salvaguardar seu estilo de vida orientado no sentido da afirmação viril ${ }^{2}$; desvalorizou, assim, o que as investigações psicanalíticas tinham proporcionado de mais valioso. Também Jung acentuou, de início, o conflito atual, afirmando que os pacientes plasmavam fantástica e regressivamente conflitos e complexos infantis, muitos dêles postulados erradamente como originais ${ }^{11}$.

Mas as criticas sôbre o excessivo "biologismo" de Freud e conseqüente valorização do sexual em detrimento do cultural vieram, com bem maior ênfase, com a chamada corrente culturalista, destacando-se os nomes de K. Horney, E. Fromm, A. Kardiner, H. S. Sullivan. Horney ${ }^{10}$ considera a vontade de poder como mecanismo de defesa; deu valor aos fins neuróticos, admitiu uma angústia básica, acentuou a situação atual, a necessidade de afeto do neurótico e criticou fortemente a teoria da libido: nem todos os afetos têm base sexual, como também há outras fontes de prazer além da satisfação sexual. Horney critica tal teoria como demasiado unilateral e insuficiente para explicar estruturas caracterológicas de grande complexidade; admite que o homem é regido pela necessidade de obter satisfação e segurança; a ansiedade básica é definida como sentimento de impotência diante de um mundo hostil. E escreve: "de acôrdo com tal conceito, a criança nāo sòmente teme punição ou abandono por causa dos impulsos proibidos, mas sente o ambiente como ameaça a seu inteiro desenvolvimento e aos seus mais legítimos desejos e tendências" 10a (pág. 75). Horney designa aquelas tendências cujo poder é determinado sobretudo por 
uma busca de segurança como "tendências neuróticas", aproximando-se tal conceito do que Freud designa como "impulsos instintivos" e "superego". Enquanto que Freud admite a natureza biológico-instintiva das necessidades irresistiveis do neurótico, Horney concebe-as como necessidade da criança de enfrentar um ambiente difícil e hostil, como meios para aquisição do sentimento de segurança. Fromm ${ }^{7}$ põe também grande ênfase sôbre os fatôres culturais, acentuando as novas necessidades trazidas pela cultura, desenvolvendo-se tendências de submissão ou ambição, por exemplo, em função de certas exigências socioculturais; admite que o comportamento sadomasoquista, certas tendências à agressividade são meros mecanismos de fuga, como o é igualmente a excessiva submissão ou um comportamento demasiado conformista; considera o complexo de Édipo como expressão da luta da criança para se libertar da excessiva autoridade dos pais, como é o caso na sociedade patriarcal, procurando ela afirmar-se por si mesmo; não dá importância ao que é fundamental na concepção freudiana, isto é, o psicodinamismo sexual de tais situações intensamente conflituosas. Sullivan ${ }^{18}$ também destaca o problema das relações interpessoais, acentuando a busca do prazer e da segurança bem como a ação de fôrça pessoais e sociais; desenvolveu tôda uma teoria do dinamismo do ego, suas relações com a angústia, e criou o conceito da deformação paratáxica, bem próximo à situação de "transferência" da psicanálise; formulou tôda uma teoria do desenvolvimento da personalidade, que descreve segundo o processo de aculturação e que divide em seis períodos (primeira e segunda infância, juvenil, pré-adolescência, adolescência e período adulto); pōe ênfase sôbre os fatôres culturais, desvalorizando a contribuição da sexualidade, cuja influência já se vai fazendo sentir na pré-adolescência e atinge sua plenitude na adolescência. Em suma, podemos dizer que Horney, Fromm e Sullivan e, com êles, os demais arautos da corrente culturalista, acentuam os fatôres ambientais, socioculturais a tal ponto que o instintivo, o biológico e, portanto, a influência dos instintos sexuais, fica bem reduzida em significação, renegando vitalmente as fundamentais aquisições da investigação psicanalítica.

Estudos de antropologia cultural sôbre que, em grande parte, se apoiam os citados autores, trouxeram fortes criticas à ação dos fatôres instintivo-sexuais no des€nvolvimento da personalidade e de sua influência nas instituiçōes e costumes socioculturais, rejeitando, sobretudo, o caráter universal do complexo-chave da teoria psicanalitica, o complexo de Édipo. A teoria da horda primitiva e do assas. sinato do chefe-pai, com a subseqüente união dos filhos assassinos para honrar e reverenciar, por angústia e culpa, o simbolo totêmico representativo do pai morto, tal como foi exposta por Freud no "Totem e Tabu"s, tem sido fortemente criticada. Muitos dos dados fornecidos por James Frazer, sôbre que a obra foi baseada, foram negados ou sujeitos a interpretações diversas pelos modernos antropólogos. Malinovski ${ }^{14}$ nega a universalidade do complexo de Édipo, citando familias matrilineares de ilhas melanésias em que tal complexo não existe por não se realizar a situação triangular da familia patriarcal. Geza Roheim ${ }^{17}$ mostrou que muitas culturas são dominadas por predominâncias orais (tribos da Austrália) ou anais, como ressalta em suas instituições, mitos e tradição folclórica, todos com as caracteristicas dessa "regressão". Tal fato não nega a influência do complexo de Edipo, acentuando apenas as defesas por regressão para fases pré-genitais, como é o caso na psicopatologia individual. Ruth Benedict (cit. por S. Nacht ${ }^{16}$ ) descreve culturas independentes umas das outras, não havendo hierarquia delas, como pen- 
sou Freud no seu esfôrço por comparar instituições culturais com as várias fases do desenvolvimento individual. Mead 1: verificou que em Samoa não há condições para a manutenção de laços específicos entre pais e filhos, numa só casa havendo irmãos, irmãs, primos, primas sem proibições sexuais, além de adultos, sendo dividido o afeto algo dispersamente entre todos. Não existe, pois, o complexo de Édipo simplesmente por não existirem as condições fundamentais para seu desenvolvimento (situação triangular). Não posso me deter aqui na apreciação de tais criticas, algumas justas, outras não. A negação do complexo de Édipo em tais culturas pode não ser de todo correta. Se fosse realizada uma análise mais profunda de tais situações, como fazem notar Nacht, Diatkine e Recamier ${ }^{16}$, poderíamos vê-lo, nāo de forma direta, mas deslocado para figuras substitutas (há separação rigorosa entre irmãos e irmãs nos povos da ilha de Trobiand estudados por Malinovski, pesando fortemente sôbre êles, após a puberdade, o tabu sexual, como é freqüente na psicopatologia individual: elementos anais e excrementiciais nos neuróticos compulsivos com defusão de sadismo, como defesa contra a situação edipiana).

Os fatôres ambientais familiares e socioculturais foram admitidos por Freud, mas talvez não com a ênfase necessária. Tem sido o mérito da neopsicanálise culturalista atrair a atenção para a grande importância dêles na personalidade normal e mórbida. Também dentro da moderna teoria e prática psicanalistas já houve certa modificação quanto à supremacia dos instintos sexuais, desde que Freud mostrou a importância dos instintos de morte, de agressão (1922). Freud parece não ter elaborado clìnicamente em grau suficiente sua nova teoria dos instintos (aplicou-a em alguns dos seus estudos sôbre sadomasoquismo, guerra, criminalidade), mas, desde a publicação do "Ego e o Id" 5i e com o livro de Ana Freud 6 , o acento foi de certa forma deslocado para o estudo do ego e seus mecanismos de defesa. As influências repressoras do superego, as ansiedades e a culpa como motivo da defesa, passaram a ter bem maior importância que a mera consideração do aspecto instintivo da personalidade (do id). Os estudos da escola inglêsa ${ }^{12,13}$ vêm acentuando o papel dos instintos de morte $\mathrm{e}$ de agressão na personalidade normal e nos vários quadros mórbidos, revelando que a angústia, o sentimento de culpa, a ansiedade persecutória e a depressiva, estão em conexão, sobretudo, com os instintos de morte, com os impulsos agressivos da criança para os objetos primários e o mêdo de represália sob forma de destruição do ego (angústia persecutória) ou da ameaça de perder o objeto amado, o bom objeto (angústia depressiva). Trouxe, assim, a referida escola novos motivos de desvalorização relativa dos instintos sexuais como agente etiológico, em beneficio dos agressivos. Até pelo contrário: as fantasias e atitudes sexuais visam atos de reparação, de vida, para neutralizar os efeitos catastróficos dos instintos de morte atuando no interior e defletidos para fora em ataque aos objetos primários (mãe nas primeiras fases). Os instintos agressivos seriam os patogênicos, quando o ego não tivesse êxito nas defesas muito primárias postas em ação (projeção, idealização, onipotência, cisão dos aspectos bons e maus dos objetos e do próprio ego, etc.). Quer se aceite a teoria dos instintos de morte ou se considere a agressão como mero efeito secundário das frustrações amorosas, o fato inegável é que goza ela papel importantíssimo em psicopato- 
logia, quase usurpando a supremacia dos instintos sexuais dos primeiros tempos da investigação psicanalítica. No desenvolvimento normal da personalidade assistimos a um relativo equilíbrio entre Tanatos e Eros, entre instintos de morte destrutivos e os instintos libidinosos de vida, êstes últimos, segundo M. Klein, visando neutralizar os efeitos catastróficos dos primeiros. Vemos, então, que as elaborações das defesas do ego utilizam a energia sexual amorosa para compensar, neutralizando, a energia dos instintos de morte que, sob forma de objetos maus interiores, atacam o ego, forçando a defesas ainda muito primárias. Tal relativa subestimação dos instintos sexuais em favor dos instintos de morte na teoria kleiniana tem sido criticada pela corrente de psicanalistas que segue a linha mais clássica freudiana. Todavia, tal teoria parece já vencedora, e o interêsse se deslocou marcadamente para o estudo das fases pré-genitais, pré-edipianas, com estudos e investigações, aliás, iniciados pelo próprio Freud ${ }^{5 i}$, perdendo o complexo de Édipo aquela importância central dos primeiros tempos, cada vez mais sendo concebido, não como início ou centro de um longo e complexo desenvolvimento psicossexual, mas já como término de uma fase evolutiva iniciando-se logo após o nascimento e terminando ou esmaecendo imediatamente antes do período de latência. A análise de criança como a de psicóticos vem sempre confirmando e proporcionando novos dados sôbre a primacial importância dessas fases pré-genitais com acento sôbre os instintos sádicos, de agressão, cuja importância, vista por Freud, foi objeto de estudos profundos por $\mathrm{K}$. Abraham principalmente ${ }^{1 \mathrm{a}} \mathrm{b}$, até assumir grande importância na escola inglêsa. Mais recentemente, Hartmann ${ }^{8,9}$ vem desenvolvendo a teoria de certa autonomia do ego: não se desenvolve diretamente de id sob ação do meio exterior, como foi postulado por Freud, mas ambos se desenvolveriam de uma matriz comum, havendo na estrutura do ego tôda uma espécie de zona neutra, não cọnflituosa. Tais concepções vêm tendo progressiva aceitação, atraindo o interêsse de psicólogos e psicanalistas para o problema do desenvolvimento primitivo do ego com seus núcleos iniciais já em plena fase intra-uterina.

Representam tais estudos uma subestimação ou perda de valor da teoria dos instintos em psicologia normal e em psicopatologia? Não acredito. Pelo contrário: vejo em tal movimento de crítica e ajustamento o resultado da reflexão mais amadurecida sôbre novos dados trazidos por tôda uma série de investigaçōes sòmente possibilitadas pelo método psicanalítico profundo, necessàriamente orientado para os planos mais instintivos da personalidade. Sente-se que a nova psicologia analitica do ego vai se formando e se cristalizando em bases sólidas, porque é apoiada sôbre grande massa de trabalhos e aquisições desconhecidos antes do advento da técnica psicanalitica de investigação. Freud, com o "Para Além do Princípio do Prazer" (1922) e o "Ego e o Id" (1923), foi o iniciador de tôda essa nova fase de estudos que vem se revelando frutífera. Sente-se que a psicologia do ego vai agora 
recebendo contribuições dos mais variados campos, sem que sejam prejudicadas as bases instintivo-afetivas de sua estruturação e desenvolvimento. A angústia foi reinterpretada por Freud ig: não é apenas mera conversão de energias instintivas sexuais em fenômenos de inervação do sistema neurovegetativo, mas é algo que se localiza no ego, como sinal de advertência em face de situações reais ou inconscientes (mêdo e angústia neurótica, respectivamente). O problema do ego-superego, sobretudo no campo das psicoses e da deliqüência ocupa o primeiro plano: assiste-se, nos vários quadros da nosologia mental, a reações de fuga, de alteração da realidade nos fenômenos ilusórios, alucinatórios e delirantes, à fragmentação do ego, que passa a funcionar como núcleos mais ou menos autônomos, na esquizofrenia grave; ou então, a realidade é apreendida e interpretada segundo tôda uma poderosa constelação ídeo-afetiva apoiada em realidades internas sentidas como perigosas, no delírio interpretativo-persecutório paranóico, no sensitivo de auto-referência, em querelantes e nos diversos quadros das psicoses passionais; ou, ainda, conflitos são projetados, vivenciados e atuados no mundo exterior, nas personalidades psicopáticas e nos caracteres neuróticos, que vivem aloplàsticamente seus conflitos vitais. Os estados de ansiedade e culpa de motivação inconsciente, as angústias persecutórias e depressivas passaram a dominar a cena em psicopatologia e são revividos na situação transferencial psicoterápica; podem ser manipulados e elaborados no "aqui e agora" pelo psicoterapeuta. Êste vai ajudando o paciente a dissolver os mecanismos neuróticos e psicóticos deformados e deformadores, entrando gradativamente numa realidade mais objetiva, menos ansiosa, menos terrificante, até atingir o plano da higidez mental. Num plano menos clínico porém mais transcendental de reflexão filosófica, assistimos talvez à bela perspectiva do encontro de tais aquisições da psicologia profunda dinâmica com as modernas elaboraçōes da filosofia fenomenológico-existencial sôbre os problemas da angústia, do mêdo e do nada, do tédio e da melancolia, da morte e do desespêro. Através de tôda uma brilhante plêiade de pensadores (Kierkegaard, Nietzsche, Husserl, Heiddegger, Jaspers, Sartre, Gabriel Marcel e tantos outros), aflui tão poderosa corrente de pensamento filosófico-existencial para o campo da psicopatologia e da clínica psiquiátrica com os notáveis e fundamentais trabalhos de L. Binswanger ${ }^{3}$. É , sem dúvida, uma vigorosa corrente de pensamento, que se propõe a prolongar o plano de investigação para o problema do sêr totalitário, com seus problemas ontológicos e existenciais, incluindo-o, assim, num âmbito mais amplo de apreensão e compreensão.

Haverá o perigo de perder a Psicopatologia algo de sua solidez científica, resvalando para indagações e elocubrações filosóficas, como adverte o próprio Jaspers, que tanto talento demonstra em manter separados os campos da ciência e da filosofia? Há tal perigo, mas, a meu ver, não é êle insuperável. Uma ciência que lida com problemas tão sutis como o da psique humana não terá necessidade, mais que qualquer outra, de um bafejo da filosofia, sobretudo se esta não se deixa orientar por divagações escolástico-religiosas algo estéreis, senão que parte e permanece, sobretudo, 
estudando o homem concretamente inserto no seu meio, isto é, o homem em situação? Parece que os psicopatologistas fenomenológico-existenciais, que muito se abeberaram em Husserl, Heidegger, Jaspers e, mais recentemente, em Minkowski e Binswanger, têm uma mensagem de grande importância a nos enviar. Seja ela bem-vinda, se contribuir para aumentar nossos conhecimentos e remover certas insuficiências que ainda sentimos no trato cotidiano com nossos pacientes. Nesse complexo tabuleiro da personalidade psicofísica, enormes são os problemas variáveis, desde o mais lìdimamente instintivo-biológico, através do sociocultural tão entusiàsticamente estudado pela moderna antropologia cultural, até os grandes problemas ônticos e ontológicos do sêr em seu mundo. O "Dasein", o "in-der Welt-sein" de Heidegger convida-nos a dúvidas e reflexões sôbre sua estruturação e transcendência e, por certo, não serão elas sem fundamento e sem utilidade porque se refletem no nosso grau e capacidade de compreensão dos nossos pacientes. Quanto mais penetramos em seu intimo, mais capazes estaremos de ajudá-los, o que é o grande escopo não só do psiquiatra e psicoterapeuta, mas de todo o médico digno dêsse nome. Nesse complexo psicodinamismo o plano biológico-instintivo é, por certo, fator de máxima importância; entretanto, deve ficar em seu lugar, sem pretensões de onipotência. A reavaliação do papel dos instintos sexuais em Psicopatologia não pode dispensar a consideração dos demais fatôres e aspectos da personalidade total.

Resta-me a esperança de que, com as restriçōes, limitaçōes e correções que procurei transmitir, não tenha eu dado a impressão de qualquer subestimação da obra de Freud. Não se pode subestimar um gênio, mas a melhor forma de honrá-lo e reverenciá-lo consiste em apontar suas grandes intuições e descobertas sem ocultar os pontos em que sua mensagem pode sofrer restrições e modificações.

\section{RESUMO}

O autor analisa a contribuição da teoria da libido, postulada por Freud, para o esclarecimento de certos problemas básicos da psicopatologia. Refere-se aos trabalhos fundamentais sôbre os instintos sexuais na primeira fase do movimento psicanalítico, sobretudo às contribuições pioneiras de Freud e Abraham. Após mencionar o movimento dissidente de Adler e Jung, passa a estudar a contribuição dos neopsicanalistas de orientação culturalista (Horney, Fromm, Kardiner, Sullivan), comentando seu ponto de vista fundamental: a predominância dos fatôres socioculturais e desvalorização do "biológico" na personalidade normal como na mórbida, sobretudo no âmbito da psicologia social e na moderna antropologia cultural. O autor procura analisar problemas tão complexos em têrmos de convergência e não como oposições rígidas entre o biológico e o sociocultural, admitindo que o aspecto instintivo da personalidade tem grande importância mas não esgota os problemas psicodinâmicos extremamente complexos da personalidade total. 
SUMMARY

The importance of sexual instincts in Psychopathology.

The author analyses the contribution of Freud's libido theory for the elucidation of certain basic psychopathologic problems. After mentioning the dissident ideas of Adler and Jung, he studies the contribution of the neo-psychoanalysts with cultural orientation (Horney, Fromm, Kardiner, Sullivan) referring their fundamental point of view: the predominance of sociocultural factors and devaluation of the biological ones in the development of normal and abnormal personality, especially on social-psychologic and cultural-anthropologic principles. Considering these biological and sociocultural aspects as convergents and not as opposites the author concludes that the instinctive level of the personality is very important, but not sufficient to explain all the psychodynamic problems of the personality.

\section{REFERENCIAS}

1. ABRAHAM, K. - a) Contributions to the theory of the anal character (1921); b) The influence of oral erotism on character-formation (1924); $c$ ) A short study of the development of the libido, viewed in the light of mental disorders (1924). In Selected Papers. Trad. por D. Bryan e A. Strachey. Hogarth Press, Londres, 1927. 2. ADLER, A. - a) Study of Organ Inferiority and its Psychical Compensation. Trad. por S. E. Jelliffe, Nova York, 1917; b) El Caracter Neurótico (1912). Trad. por A. von Ritter-Zahóny e P. F. Valdes, Ed. Paidos, Buenos Aires, 1954. 3. BINSWANGER, L. - a) Über Phänomenologie; b) Uber die daseinsanalytische Forschungsrichtung in der Psychiatrie. In Ausgewählte Vorträge und Aufsätze. Band 1, A. Francke Ag. Verlag, Berna, 1947. 4. BREUER, J.; FREUD, S. - On the Psychical Mechanism of Hysterical Phenomena: Preliminary Communication (1893). Standard Ed. of the Compl. Psychological Works of S. Freud, vol. 2, Hogarth Press, Londres, 1955. 5. FREUD, S. - a) Three essays on the theory of sexuality (1905). Standard Ed, of the Compl. Psychological Works, vol. 7, Hogarth Press, Londres, 1953; b) Totem and Taboo (1912-13). S. E. C. Psychol. Works, vol, 13, Hogarth Press, Londres, 1955; c) Beyond the pleasure principle (1922). Standard Edition, vol. 18, Hogarth Press, Londres, 1955; d) Observaciones psicoanaliticas sobre un caso de paranoia (dementia paranoides) autobiográficamente descrito (1911). Ed. castelhana das Obras Completas, vol. 16, Madrid, 1932; e) Introducción al narcisismo (1914). Ed. castelhana das Obras Completas, vol. 14, Madrid, 1930; $f$ ) El yo y el ello (1923). Ed. castelhana das Obras Completas, vol. 9, Madrid, 1934; $g$ ) Inhibición, sintoma y angustia. Ed. castelhana das Obras Completas, vol. 11, Madrid, 1934; h) Los instintos y sus destinos. Ed. castelhana das Obras Completas", vol. 9, Madrid, 1934; i) La feminidad. Ed. castelhana das Obras Completas, vol. 17, Madrid, 1934. 6. FREUD, A. - Das Ich und die Abwehrmechanismen. Internat. Psychoanalytischer Verlag, Viena, 1936. 7. FROMM, E. - a) Man for Himself. Rinehart and Co., Nova York, 1947; b) El Miedo a la Libertad. Trad. por Gino Germani, 4" ed. Ed. Paidós, Buenos Aires, 1958. 8. HARTMANN, H. - a) Mutual Influences in Development of Ego and Id. The Psychoanalytic Study of the Child, vol. 7. Intern. Univ. Press, Nova York, 1952; b) Contribution to the Metapsychology of Schizophrenia. The Psychoanalytic Study of the Child, vol. 8. Intern. Univ. Press, Nova York, 1953. 9. HARTMANN, H.; KRIS, E.; LOWENSTEIN, R. M. Comments on the Formation of Psychic Structure. The Psychoanalytic Study of the Child, vol. 2. Intern. Univ. Press, Nova York, 1947. 10. HORNEY, K. - $a$ ) New Ways in Psychoanalysis. W. W. Norton Co., Nova York, 1939; b) Our Inner Conflicts. W. W. Norton Co., Nova York, 1945; c) Neurosis and Human Growth. W. 
W. Norton Co., Nova York, 1950. 11. JUNG, C. C. - a) Transformaciones y Simbolos de la Libido. Ed. Paidós, Buenos Aires, 1952; $b$ ) El Y y lo Inconsciente. Trad. por S. Monteserrat Esteve. Luis Miracle ed., Barcelona, 1936; c) Symbols of Transformation. Trad. por R. F. C. Hull Routledge e Kegan Paul, Londres, 1956. 12. KLEIN, M. - a) The Psycho-Analysis of Children. Trad. inglêsa por A. Strachey, $2^{4}$ ed., Londres, $1937 ; b$ ) Contributions to Psycho-Analysis (19211945). Hogarth Press, Londres, 1948. 13. KLEIN, M.; HEIMANN, P.; ISAACS, S.; RIVIERE, J. - Developments in Psycho-Analysis. Hogarth Press, Londres, 1952. 14. MALINOwSKI, B. - Estudios de Psicologia Primitiva. Ed. Paidós, Buenos Aires, 1949. 15. MEAD, M. - Coming of Age in Samoa. Morrow, Nova York, 1928. 16. NACHT, S.; DIATKINE, R.; RECAMIER, P. C. - Psychanalyse et sociolozie. Rev. Franç. de Psychanal., 21:2, 1957. 17. ROHEIM, G. - a) The Edipus complex, magic and culture. In Psychoanalysis and the Social Sciences. Intern. Univ. Press, Nova York, 1950; b) Psychoanalyses and Anthropology. In Psychoanalysis To-day. Intern. Univ. Press, Nova York, 1944. 18. SUllivaN, H. S. - a) Conceptions of Modern Psychiatry. William Alanson White Psychiatric Foundation, Washington, D.C., 1947; b) Introduction to the study of interpersonal relations. Psychiatry, vol. $1,1938$.

Avenida Pacaembu, 1182 -- São Paulo, Brasil. 